\title{
"TRANSMEDIAL AESTHETICS IS ORDINARY": SOME REMARKS ON VICTOR ERICE'S THE SPIRIT OF THE BEEHIVE
}

\author{
Jan Baetens \\ University of Leuven, Belgium \\ jan.baetens@arts.kuleuven.be
}

\begin{abstract}
Focusing on Victor Erice's 1973 movie, The Spirit of the Beehive, this article proposes to rethink the problem of adaptation with the help of the concept of "experience" (freely borrowed from Dewey). The emphasis on the reception of a given work (in this case James Whale's 1931 Frankenstein, a very particular screening of which is part of the movie's diegesis) will foreground the importance of the process of intermedialization or "intermediality in action," an all-encompassing culturally embedded experience, which is more existential than aesthetic.
\end{abstract}

\section{Résumé}

A partir d'une analyse de L'Esprit de la ruche, un film de Victor Erice de 1973, cet article propose de repenser le problème de l'adaptation à l'aide du concept d' « expérience » (librement inspiré de Dewey). En insistant sur la réception d'une œuvre (en l'occurrence le Frankenstein de James Whale, 1931, dont une projection très particulière est au cœur de la diégèse du film), on peut mettre en avant l'important du processus d'intermédialisation, que l'on entendra comme « intermédialité en action », soit une expérience totale de nature plus existentielle qu'esthétique.

Keywords

adaptation, experience, Frankenstein, ghost, intermediality

\section{About the author}

Jan Baetens is professor of cultural studies at the University of Leuven. His main research interests are word and image studies, mainly in the so-called minor genres (photonovel, graphic novel, novelization). His most recent publications are a double guest-edited volume of Poetics Today on constrained writing (Vol. 30.4, 2009, and 31.1, 2010) and a book-length study on the photonovel, Pour le roman-photo (Brussels: Les Impressions Nouvelles, 2010). Jan Baetens has also published ten books of poetry, including a "novelization in verse" of Jean-Luc Godards's movie Vivre sa vie (Vivre sa vie. Une novellisation en vers du film de Jean-Luc Godard, Brussels: Les Impressions Nouvelles, 2005).

Author's note

Many thanks to Domingo Sanchez-Mesa, Steven Surdiacourt, Thomas Van Parys, as well as to the two anonymous reviewers of Kritika Kultura for their critical reading of a draft version of this article.

\section{INTERMEDIALITY NOW}

This article has a double focus, but a single ambition. It deals with both a specific-and I believe very important-film, Victor Erice's The Spirit of the Beehive (El espíritu de la colmena, 1973), 
and a very general theoretical issue, that of intermediality -in this case linked with the notion of adaptation. My aim is not in the first place to propose a completely new interpretation of Erice's film (although I hope of course that my reading may be helpful to all those who have started reading The Spirit of the Beehive in light of the current interest in crosscultural relationships within world auteur cinema, as demonstrated by the systematic gathering of Victor Erice and Abbas Kiarostami). Neither do I want to offer a new theory of intermediality despite the renewed curiosity for this topic in word and image studies (Elleström). What I will try to do is to see whether both The Spirit of the Beehive and the concept of intermediality can prove mutually helpful when one brings them together in a single analysis taking into account a certain number of new perspectives introduced by screen cultural studies - first of all the importance of the film's reception, and second the significance of the historically shifting nature of this reception.

The Spirit of the Beehive offers a wonderful opportunity to reflect upon these features, given both the role of film as cultural practice within the diegetic world (the central aspect of Erice's plot has to do with the viewing of a film, James Whale's 1931 horror movie Frankenstein, by the protagonist, the six-year-old Ana), and the film's insistence upon the diverging and successive interpretations of this viewing: Ana does not interpret Frankenstein the same way as the others, and her interpretation of the film, which will prove a short-cut for her interpretation of life in general, will not stay the same in the duration of the film. As far as the issue of intermediality is concerned, its usefulness as an object of analysis from a cultural point of view has to do with the fact that very often it has been privileged as the favorite playground of formal and formalist analysis. I would like to show here that such a formalism does not exhaust the meaning of intermediality.

Since it is not my intention to make big statements on what intermediality (the relationship between media) or transmediality (the shift or transfer from one medium to another) as such may be or signify in general, either as semiotic object or social practice, I will use these terms in their traditional, widely accepted meaning, as summarized for instance in excellent studies by Irene Rajewsky, who continues the pioneering work of Claus Clüver and of Henry Jenkins, who has opened the field to the wider social context of the cultural industries (Hesmondalgh). As I am more interested in the encounter of a theoretical framework with a specific work, I would like to start with a critical mention of two possible dangers or obstacles in the study of intermediality and transmediality - on the one hand, the taxonomic "derive" or drift, for it can be easily observed that various studies are mainly interested in endlessly describing the "what" and "how" while overlooking the more challenging aspects of the "why," and on the other hand, a certain analytical vagueness that accompanies the a priori praise of hybridization, which tends to become a term whose medial complexity has no longer to be analyzed (for a polemical dialogue with intermedial 
studies that foreground hybridization as a kind of black box at the expense of concrete analysis of medial complexities, see Elkins 112-13 and Manovich 15).

One of the recent victims of these two dangers may be adaptation studies. The author of a recent article in adaptation studies, Christine Geraghty (see also Kranz), rightfully argues that the critique of the so-called fidelity issue has produced felicitous effects as well as infelicitous sideeffects: it has freed adaptation studies from a dangerous myth, yet it has also made adaptation studies almost impossible:

the post-structural emphasis, in seeking to throw out the hierarchical values of the fidelity model, runs the risk of also throwing out the notion of an adaptation altogether. If the notion of an original source with an overdetermining author is dropped, if all texts depend on an interplay of cultural references and sources, if collage rather than écriture is the dominant mode of writing, then all texts "are caught up in an ongoing whir of intertextual referenced and transformation, of texts generating other texts in an endless process of recycling, transformation, and transmutation, with no clear point of origin." (Stam qtd. in Geraghty 94)

Against the danger of the vanishing of specificities (specificity of concrete works, genres, mechanisms, but also specificity of concrete practices and contexts), I would like to stress the usefulness, if not the necessity, of rooting theoretical reflection in the reading of concrete works, as exemplified for instance in Stanley Cavell's work on the notion of medium. Cavell emphasizes very strongly the role and place of specific works, for it is only through these concrete occurrences that media are shaped, invented, or transformed (for a brief presentation, see Baetens, "Le roman photo"). In this case, The Spirit of the Beehive might provide us with a stimulating example, given the importance of intermedial aspects and questions in this movie.

\section{THE SPIRIT OF THE BEEHIVE, AN INTERMEDIAL WORK?}

The film tells the story of two little girls and their parents who live in a small rural village some years after the end of the Spanish Civil War (1936-1939). Although life in this village seems to have come to a complete stand-still, time and history are there from the very beginning till the very end of the film: the parents try to cope in silence with the effects of the War, the children slowly discover what it means to grow up and the learn the difference between real and unreal, between good and bad (the two questions are inextricably linked in the movie). The beehive mentioned in the title has many meanings: literally, it refers to the professional activity of the father, who is a bee- 
master; symbolically, it represents the family, the village, the country, and the impossibility for an individual to survive as an individual without surrendering to the larger whole. The spirit refers not only to the fictional beings the girls discover during a film projection, but also to the dead who, in the fantasy of children, may still be around. Yet it also refers to the partisan (a republican solider who goes on fighting inside the country against Franco) who hides in the place where the children go out to play. The younger one, Ana, seems to believe-even if in an ambivalent, hesitating waythat the partisan is "her ghost," i.e., a dead person she believes she can make appear by saying her name, "Soy Ana" ["It's me. Ana"]. Yet for outsiders there is no such place in the society and the deserter will be shot by the police. It is a traumatizing episode for Ana who doesn't understand why the ghosts are no longer responding to her summons, and who suspects her father to have played a bad role in the events.

Produced on a shoestring budget during the last years of the Franco regime (1939-1975) and winner of one of the most important Spanish film prizes (the "Golden Shell" of the San Sebastian Film Festival at its release in 1973), The Spirit of the Beehive is representative of the local production of that period, yet not very well known to the larger audience despite its being widely recognized as a masterpiece of Spanish cinema (Pena; Smith). The reasons for the work's relatively marginal and paradoxical status are manifold: compared to other Spanish directors of that period (either working in Spain, like Saura and, slightly later, Almodovar, or outside the country, as Buñel), Erice has made very few films, and his introvert, if not frankly shy, personality is reflected in his films that do not appeal to a large audience (spectators tend to be bored by the films' slow rhythm). Moreover, The Spirit of the Beehive did not benefit, as did other films and filmmakers, from the automatic sympathy and publicity given to anti-Franco films because its political meaning is considered too vague by contemporary critics. Nevertheless, Erice's movie is very typical of the kind of art house cinema that was being made at the end of the Franco dictatorship. Trying to offer a positive view of Spain and Spanish political and cultural life, the regime tolerated and, to a certain extent, encouraged the production of small-budget-quality films (i.e., auteur's cinema) mainly aimed at the international, European market. These films were allowed a certain number of creative and political liberties unknown to those producing for the domestic market dominated by crude comedies. But this freedom was limited: openly critical or leftist cinema was unthinkable, and filmmakers would use indirect forms of critique, hence the frequent use of allegorical representations and children as main characters, two well-known "symptoms" of artistic critique in difficult political situations. In The Spirit of the Beehive, "Frankenstein" is clearly such an allegory, and the framing of the allegory through the eyes of a child helps keep it as vaguely allegorical as possible (the analogy with today's Iran is so evident that it is almost superfluous to stress it, and the association of Erice and Kiarostami is of course not a coincidence). The film's reception has exactly the same ambivalent 
status as the work itself. Although immediately acclaimed as a masterpiece, The Spirit of the Beehive also had many critics (leftist authors and spectators condemned its lack of direct political critique). However, the quarrel between defenders and enemies of the film was never very heated, since the film itself was so delicate and discreet that it never provoked a real clash. A typical art house movie, The Spirit of the Beehive only gained a large audience at the celebration of the thirtieth anniversary of its release, when the film was eventually acclaimed as an icon of Spanish cinema (finally enabling the American release in 2007).

The relevance of Erice's film for intermedial studies is self-evident not only because it is a "film" -i.e., a medium that is traditionally considered an intermedial structure, a syncretic montage of various media - but also because it is an adaptation of various sources: art-historical (many tableaux in the film are creative treatments of Vermeer's interior paintings), literary (Maurice Maeterlinck's The Life of the Bee [1901], with the beehive as metaphor for life in post-Civil War Spain wherein the individual is inevitably sacrificed to the community), and most prominently cinematic (James Whale's Frankenstein), the latter deeply determining the form and meaning of Erice's movie and often read - for me, in a superficial way - as an allegory for general Franco as the "monster."

All these observations and interpretations are correct, yet unsatisfying, for they do not make us see what is really happening in the film. In other words, on stating that The Spirit of the Beehive is a work that combines various media (intermediality in praesentia) while referring to various other media (intermediality in absentia), one doesn't say anything about the proper intern logic of the film in which other mechanisms are more paramount. What the film really is about is actually something else.

First of all, Erice's movie insists a lot on the deconstruction of its source materials, which are often reworked in elliptic ways: the non-said is the basis of his aesthetics. Maeterlinck's book is thus reduced to a couple of short quotations, which are not even presented as quotations at all, but as part of a letter written by one of the characters or as part of a text written by another character. As far as Whale's film is concerned, this approach of erasure and dissimulation goes even further. In Erice's movie, Whale's film is dramatically present, since Ana assists in a projection of Frankenstein in an improvised rural theatre. At the same time, it is shown in a mutilated way, for we as spectators of The Spirit of the Beehive see only snippets of Frankenstein and the crucial scene of the killing of the girl remains absent. The keyword here is negativity, and a reading that simply recovers all the missing links and references would be a reading that misses the specific way in which The Spirit of the Beehive "uses" intermediality. And what can be said of intermediality in absentia (the intertextual dimension, if one prefers) is repeated at the level of intermediality in praesentia, since the film proposes a very audacious montage with many "gaps" which are not 
compensated or filled-in by dialogues (in a sense, one might say that Erice has shot a silent movie with sound technology; see Pena).

Second, and most decisively, The Spirit of the Beehive does not really focus on the combination of media. It foregrounds instead the reception by an audience. What matters is how fictional characters make sense of the film within the film. The essential layer is therefore rhetorical, as shown in the integration of James Whale's Frankenstein in the very plot of the The Spirit of the Beehive. If parts of Frankenstein are shown within The Spirit of the Beehive, greater weight is given to commentary of Frankenstein, first by the "bonimenteur" who opens the movie, and second by the questions and answers that Ana and her sister Isabel exchange during and after the projection - this being the very heart of the film, a particularly painful and traumatic coming of age story. Ana, who has still to learn the difference between fact and fiction, between good and evil, wants to know why the monster killed the little girl and what the villagers did to the monster afterwards. Her sister, older and better informed, tells her that it's just cinema, and that the dead are not dead but go on living as ghosts. Isabel moreover tells Ana that she can "call" these ghosts whenever she wants. When a stranger appears and hides from the villagers, Ana believes that he is the "ghost" she has been calling for since the Frankenstein projection, and she will not understand why the man, who will be shot by the police, is suddenly no longer there. Yet since she also discovers traces of blood in the barn where she and her soldier-ghost have been meeting, she starts to realize that the ghost is perhaps not a ghost but a real person, and her suspicions turn to her father who previously explains the difference between innocent and dangerous but inoffensively looking mushrooms (and thus between reality and fiction, protection and danger, right and wrong, good and evil). She runs away from home, and at the end of her journey, the monster waits for her. In short, what we are confronted with in The Spirit of the Beehive is a cascading series of rhetorical devices that instruct us how to understand Frankenstein, and more generally the film in which James Whale's movie plays an eminent role. Yet an overall interpretive frame is lacking: we assist in the activity of watching and reacting to movies rather than offered a final reading.

\section{INTERMEDIALITY AT WORK}

The importance of the rhetorical dimension of the film can also be inferred from the way in which Erice "concentrates" various aspects of the history of cinema in his own movie. At least four different temporal layers are "blurred" in the movie:

- First, the age of the so-called "primitive" cinema, actualized in the "rewriting" of some famous silent movie fragments (the Lumière film on the arrival of a train at the station of La Ciotat), or the focus on the particular viewing conditions of Frankenstein (not those of 
a contemporary theatrical presentation but those of a travelling rural projection that can be considered typical of the primitive cinema years - and which still existed in Spain in the period wherein the story is situated);

- Second, the age of the first talking movies, via the insertion of James Whale's movie (the emphasis on the "talking" peritext, with a very "physical" announcement made by the village announcer who blows the horn to draw the attention of the villagers and then reads to them the details of the projection, underlines the complex merging of sound and sight, the inside and outside of the theatre, reality and fiction);

- Third, the period (around 1940) in which the fictional story is situated, in which the social and imaginary impact of cinema is still tremendous, with film as an exceptional event that interrupts the people's daily occupations and opens a window to a different world to an audience that is clearly deprived of contact with the outside world;

- Fourth, but not necessarily last, the "contemporary" context of the film's production year, 1973, which determines what can and cannot be said and done in a moviealthough at the end of the Franco regime, and even in the years before, film censorship could be challenged in different ways, it was not possible to make direct and explicit political statements attacking the head of the State);

- Fifth, and permanently shifting last layer, is the actual viewing of the film by its contemporary audience (for whom the historical embedding of the movie in the last years of the Franco dictatorship may have become quite abstract).

Yet, here as well, what strikes the contemporary viewer is less the notion of intermedial "collage" than global reworking and global treatment of the source material: each time a work of the past is shown or referred to, it is its total integration in a present reuse that is foregrounded. Erice thematizes the villagers' reactions to Frankenstein (to quote Alain Brossat's terminology in his corrosive attack against our current cultural and heritage regime) not as a world of "objects" and "memories," but as a world of "actions" - or, if one prefers, not as a world of "culture," which looks at the past, but a world of "politics," which looks at the future (Brossat 56). What is asked from the audience is not to adopt a genealogical point of view that tries to identify sources and beginnings (in this case a reflection on the history and evolution of cinema), but a kind of (political?) action - if possible, an action different from the lack of any action displayed by the prisoners of the beehive they are watching on screen.

The proximity of (fictional) character to (actual) audience, for both are "forced" to make sense of something they do not necessarily understand, is what separates The Spirit of the Beehive from other works that display the tricky confusion of fiction and fact. Ana, the little girl, who will 
eventually learn the difference between fact and fiction, and therefore also between good and evil (as the actual spectator is invited to do as well), is definitely not a Bovary of Quixote-like character who is being mocked by the artist in order to demonstrate the abyssal difference between the funny or tragic silliness of the fictional character and the superior distance shown by the knowing author and the complicit audience.

Erice's display of how intermediality works is also a lesson on how remediation works, and perhaps The Spirit of the Beehive delivers here a lesson that goes against the grain. What Erice seems to crave for is a re-enactment by the contemporary viewer of the "primitive," childish viewingand of the learning process that follows the first traumatizing contact with the Frankenstein movie. By showing the tremendous impact of Frankenstein on the children's mind, he is giving a lessonyet a very ambivalent one-on the power of cinema, for cinema both alienates and liberates. Targeting an adult audience (The Spirit of the Beehive is a movie on children, but not for children), he invites the viewers to "surrender" to the experience of Ana who first misses the difference between fiction and reality, and then to follow in her gradual disclosure of the difference between real and unreal as well as between right and evil. This intertwining of the experience of the children (on screen) and that of the adults (in the theatre) is not only linked with issues of remediation between various types of cinema (the "old" film seen by the children, the "new" film seen by the spectators in the theatre), but also with remediation issues between various type of media (film and nonfilm). Very telling in this regard is the opening sequence of The Spirit of the Beehive that presents the credits on a backdrop of children's drawings that "morph" into the real images of the film. Here as well, the line between the primitive and the sophisticated, between old and new, is very thin, if not inexistent - at least if we look at it from the viewpoint of the effect of the media. In other words, what Erice is questioning is the supposed superiority of the more evolved forms over the simpler, if not simplistic ones. When it comes to rhetorical effects, the power of the imagination, and finally meaning, formal and technological complexity is no longer an issue. The effect is not just on screen, it is in the eye-and of course also in the mind-of the beholder. Old media-old films, old theatres, old people, old books, old forms of writing - can be as efficient as newer ones, and formal and technological remediation is therefore never a goal in itself. If it is true that newer media can enhance and remediate older ones, as Bolter and Grusin argue, the contrary can be true as well. Each ambitious filmmaker tries to remediate and each curious audience is looking for new thrills, but the basic mechanism of this remediation is context-bound; it is not a matter of "harder, faster, and deeper" but of a sometimes unforeseen and unforeseeable shock. In a somewhat indirect manner, The Spirit of the Beehive foregrounds also the problem, exemplarily raised in the study of digital literature, of the increasing obsolescence of old media. It criticizes our "remediational" belief 
that the technical obsolescence of certain media jeopardizes not only our access to but also our experience of the source text.

The kind of "reception" displayed by Erice's movie - and probably also the kind of reaction that the director was expecting from his own audience-cannot be satisfactorily analyzed by the formal, taxonomic, and perhaps also aesthetic and art-historical approach. More appropriate for the reading of the intermedial character of The Spirit of the Beehive is the cultural studies approach, given the vital importance of the audience and the notion of "experience" in this approach. The first aspect-that of audience-has become a cliché. It is in accordance with postmodern preferences for the social construction of meaning and fits perfectly our deep distrust of auctorially embedded or encrypted meanings. The second aspect-that of experience-may seem more problematic.

In cultural studies, the notion of experience springs mainly from two different traditions. The first one is the pragmatist tradition of John Dewey, as illustrated in his seminal work Art as Experience and updated by Richard Shusterman in Pragmatist Aesthetics. Even though "experience" is not defined by Dewey in one clear way, it always entails a strong emphasis on the unified and unifying aspects of the concept: an experience is what transforms the relationship between an experiencing subject and an experienced object or event into something that transforms both the subject and his or her way of feeling and living the world. The second tradition is that of the "culture is ordinary" movement of the first cultural studies, that of Hoggart, Williams, and Thompson, with the notions of culture and experience rendered almost interchangeable, with culture being "a way of life" (Williams). Either line of thinking helps better understand what is happening in The Spirit of the Beehive: the projection of Frankenstein is a clear example of the culture of ordinary people (more specifically, it exemplifies in a stunning way how ordinary people living in rather extreme circumstances manage to make sense of products of the culture industry), whereas Ana's viewing of the movie shatters her naïve and innocent way of looking at the world, and forces her to find a new, although very ambivalent and painful, balance in a new environment. What is crucial here is the prominence of the "real": the experience in question is not just an aesthetic event, but an event that is rooted in real life and can transform it. Of course we know that "real art" is defined by exactly that-its possibility to change our lives. But not all art can achieve that, and moreover, art does not have the monopoly of this kind of effects ("anything," even the most "ordinary" things, can produce such an existential change). Yet what Erice stresses dramatically is the role that media are playing in the existential process of trying to come to terms with the real world's complexities. 
In The Spirit of the Beehive, the overall structure of the movie is composed in such a way that a series of "adaptations" is gradually enfolded:

- the credits sequence opens with a set of children's drawings that prove to be the ground of the fictional work itself;

- we see a leaded window, but also a metaphor of the beehive the characters are living in;

- we see an interior, and then we realize we see a painting by Vermeer;

- the children in class learn to name the parts of the human body, but these words are introduced via a patchwork of visual symbols stitched on the profile of a "paper man" (the allusion to Frankenstein is clear, as is the reference to the bi-medial character of the film, since what the children learn to do is to combine words and images);

- Ana and her sister live all kinds of small and great adventures, which are summarized/ symbolized by a nursery rhyme;

- Ana sees a man, but she first thinks that he is just a ghost, and it is only much later that she realizes that the vanished soldier is a real person;

- at the end of the film, after running away from home, she sees a ripple in the water, which becomes a fragment of the Frankenstein movie.

And, most decisively: we are looking at projected shades on a two-dimensional screen, but we do not really believe that these moving forms and colors are mere illusions, for since the experience of the movie is not only a matter of representation but also of a lived experience; the movie's sounds and images are decoded by the real audience in terms that will shift according to their actual situation. Once again, we should infer from this hypothesis that it is limiting to impoverish the film's meaning to an allegorical representation of the post-Civil War's asphyxiating coldness and horror - this is unquestionably one of the many meanings of The Spirit of Beehive, but the experiences of the living audience can go beyond this reading - or, bypass it, if one is unfamiliar with the historical and political background of the film (not an ideal situation, but not as rare as what idealizing scholars may think. For an example of audience research of a political historical film, Raoul Peck's biopic Lumumba, see Baetens and Hesling).

The film performs a shift from a transmedial "work" to a transmedial "cultural form" or "cultural practice," i.e., an all-encompassing culturally embedded experience, which is more existential than aesthetic in the narrow art-historical sense of the word. This shift transforms the notion of intermediality and transmediality in two perhaps conflicting ways: it implies, first, a minorization or minimization (in a cultural practice, there is not such a thing as an independent 
medium, since everything is intermedial or transmedial); it emphasizes, second, the importance of the dynamics of this phenomenon (in a cultural practice, it is not intermediality or transmediality but intermedialization and transmedialization that are going on).

A closer analysis of these shifts in terms of "experience" discloses a dialectic relationship between a moment of closure and a moment of opening. The closure, on the one hand, has to do with the fact that a syncretic work (i.e., a work composed of an interplay of mixed media) is polysensorially decoded, yet in such a way that it is integrated in a holistic experience that "merges" senses and media in a single whole. The opening, on the other hand, has to do with the fact that this experience is not restricted to one field: what is being experienced "pours over" to other fields, hence the importance of analogy and metonymy within it. The notion of synaesthesia might be a good shortcut or metaphor for the interaction of closure and opening that emerge in this kind of experience. Yet such a synaesthesia is more "cultural" than "physiological": a given cultural phenomenon is experientially translated (opening) into another domain (closure). Some works will prove more capable than others in producing such an opening and such a synaesthesia, yet the key element of the process is the public's experience: there is no one to one relationship between intermedial/transmedial encoding and synaesthetic decoding. Intermedial works can be "flattened," "non-intermedial" works can be "thickened," at least at the level of the spectator's experiences, and this goes for any movie, not just for The Spirit of the Beehive. One of the great marvels of Erice's movie is that it is so aware of this phenomenon, and that it displays this possible conflict between encoding and decoding within its own story. This is what The Spirit of the Beehive shows through the manifold and divergent reactions to the same "input": Ana's reaction is not that of her sister Isabel, and the same can be said of Ana's parents' interpretation of her behavior - the father may be one of the many tokens of the monster in a certain sense, but in a sense he is also the one who understands better than the mother what is really going on in Ana's mind.

This dialectic of opening and closure is characteristic of what we call "art as experience" (a category that is both broader and narrower than either "art" or "experience"): well-known examples are Proust's "Madeleine" (a world popping up in a nutshell, so to speak, and after that transferred to the universe of mere words, which readers can experience once again as the narrator sipping his biscuit in his cup of tea) or Borges's interpretation of the building of the Chinese Walland the simultaneous burning of all existing books by the emperor-architect-as an existential metaphor for poetry. I believe that similar phenomena are diegetically evoked as well as spawned in the real audience by The Spirit of the Beehive, with its typical interaction not just between fiction and fact but also, more generally, between art and life.

Concrete works and concrete, small-sized, bottom-up reflections on issues of specificity in the general discussion on intermediality are essential. Putting a strong (and exclusive) emphasis on 
Erice's film must not be seen as an attempt to avoid theoretical issues or questions, but as a defense of the importance of the lived experience and of the capacity of apparently very simple movies to make a major contribution to media history. As a matter of fact, reading films and doing theory are linked: for only films (or other works of art) that prove capable of "making history" will be worth keeping when we want to "do theory."

Since Erice's film tackles issues that can be tackled productively from a cross-cultural perspective, I hope that my reading of The Spirit of the Beehive can be of some help for a broader, culturally and linguistically open approach to a key theme in screen cultural studies: the (diegetic) discovery of film and its impact on the discovery and interpretation of life itself. Two major lines of research, at least, can be evoked here.

First of all, it should be possible to link Erice's movie to other films that present more or less the same theme, such as François Truffaut's Small Change (1976), Giuseppe Tornatore's Cinema Paradiso (1988) or Terence Davies's The Long Day Closes (1992), to take just some examples from various cinematographic and linguistic traditions. From an intermedial point of view, it also invites interesting comparisons with the description of similar scenes in literary texts, where children's movies experiences and the analogies and differences with real life experiences are recurrent as well. A superb recent example may be Jonathan Lethem's description, in his autobiographical pieces gathered in The Disappointment Artist, of his 21 (twenty-one!) viewings, as a 13-year-old boy, of the original Star Wars during the Summer of 1977. There exist of course countless collections of this kind of literarily framed cinematographic life lessons, such as, to quote also an example in nonfiction, Jonathan Rosenbaum's Moving Places (1995).

Second, another line of research may look into the reinterpretation of the blurring of the boundaries between film and life in the context of cognitive film studies and its emphasis on the notion of metalepsis. Originally borrowed from literary theory where it referred to all kinds of narratological paradoxes due to the confusion between story levels, the notion of metalepsis has now a much larger meaning, and designates an ontological transgression of universes and a blending of worlds (Pier). Cognitive narratology and cultural studies have started exploring their mutual interests and common interrogations since quite some time, and the specific topic of the visual or written representation of world-making through filmic experiences may offer new ground for mutually challenging readings (Zunshine). A better integration of film studies, more specifically of concrete close readings of movies such a The Spirit of the Beehive, can be helpful in fostering dialogue between perception studies, cultural studies, medium theory, and narrative theory. 


\section{WORKS CITED}

Baetens, Jan. "Le roman-photo: média singulier, média au singulier ?" Sociétés et représentation ( La croisée des médias») 9 (2000): 51-59.

-, and Willem Hesling. "De pluriforme filmkijker. Een kwalitatief publieksonderzoek naar de receptie van Lumumba." Tijdschrift voor Mediageschiedenis 11.1 (2008): 22-65.Bolter, Jay David, and Richard Grusin. Remediation: Understanding New Media. Cambridge, Mass.: MIT, 1999.

Borges, Jorge Luis. “La muralla y los libros.” Prosa completa. Barcelona: Bruguera, 1980. 131-33.

Brossat, Alain. Le grand dégoût culturel. Paris: Seuil, 2008.

Cavell, Stanley. The World Viewed. Cambridge: Harvard UP, 1979.

Clüver, Claus. "Intermediality and Interarts Studies." Changing Borders : Contemporary Positions in Intermediality. Eds. Jens Arvidson, Mikael Askander, Jørgen Bruhn, Heidrun Führer. Lund: Intermedia Studies Press, 2007. 19-37.

Dewey, John. Art as Experience. New York: Teachers College Press, 2001.

El espiritu de la colmena [The Spirit of the Beehive]. Dir. Victor Erice. Perf. Fernando Fernán Gómez, Teresa Gimpera, and Ana Torrent. 1973.

Elleström, Lars. Media Borders, Multimodality and Intermediality. London: Palgrave, 2010.

Erice, Victor, and Abbas Kiarostami. Correspondences. Barcelona/Madrid: Actar/La Casa encendida, 2006.

Geraghty, Christine. "Foregrounding the media: Atonement (2007) as an Adaptation" Adaptation 2.2 (2009): 91109.

Hesmondalgh, David. The Cultural Industries. $2^{\text {nd }}$ ed. London: Sage, 2007.

Jenkins, Henri. Convergence Culture. New York: New York UP, 2006.

Jullier, Laurent. "Should I See What I Believe: Audivosiaul Ostranenie and Evolutionary-Cognitive Film Theory." Ostrannenie. Ed. Annie van den Oever. Amsterdam: Amsterdam UP, 2010. 119-40.

Krantz, David. "Trying Harder: Probability, Objectivity, and Rationality in Adaptation Studies." The Literature/Film Reader: Issues of Adaptation. Eds. James M. Welsh and Peter Lev. Lanham, Maryland: Scarecrow, 2007. 77-102.

Lethem, Jonathan. The Disappointment Artist. New York: Doubleday, 2005.

Pena, Jaime. Victor Erice. El espíritu de la colmena. Estudio crítico. Madrid: Paidós, 2004.

Pier, John. "Metalepsis," The Living Handbook of Narratology. 2010. 28 May $2011<$ http://hup.sub.uni-hamburg. de/lhn/index.php/Metalepsis>.

Rajewsky, Irina O. "Intermediality, Intertextuality, and Remediation: A Literary Perspective on Intermediality." Intermédialités 6 (2005): 43-64.

Rosenbaum, Jonathan. Moving Places. A Life at the Movies. Berkeley: U of California P, 1995.

Shusterman, Richard. Pragmatist Aesthetics: Living Beauty, Rethinking Art. Oxford: Blackwell, 1992.

Smith, Paul Julian. "The Spirit of the Beehive: Spanish Lessons." The Criterion Collection. 2006. 28 May 2011 $<$ http://www.criterion.com/current/posts/447-the-spirit-of-the-beehive-spanish-lessons>.

Stam, Robert. "Beyond Fidelity: The Dialogics of Adaptation." Film Adaptation. Ed. James Naremore. London: Athalone, 2000. 57-76.

Williams, Raymond. Culture and Society. London: Chatto and Windus, 1958.

Zunshine, Lisa, ed. Introduction to Cognitive Cultural Studies. Chapel Hill, NC: Duke UP, 2010. 